\section{Hydroxychloroquine Retinal Toxicity and Its Association with Dosage}

To the Editor:

A recent clinical image of hydroxychloroquine (HCQ) retinal toxicity has been recently published ${ }^{1}$. In this case, the patient who presented with symptoms was on long-term treatment with HCQ at more than twice the recommended dose related to her weight, and the tests were consistent with established retinopathy.

HCQ retinopathy has been extensively studied lately. Recent data show an increased risk for toxicity among patients receiving doses $>5 \mathrm{mg} / \mathrm{kg} /$ day (i.e., $300 \mathrm{mg} /$ day in a woman of average weight). Otherwise, those taking $<4 \mathrm{mg} / \mathrm{kg} /$ day had a frequency of retinopathy $<10 \%$ even after more than 20 years of therapy ${ }^{2}$. A recent study in the Lupus-Cruces cohort found no relevant retinal changes measured by optical coherence tomography over a 5-year follow-up and no cases of established toxicity. The median dose of HCQ was $3.12 \mathrm{mg} / \mathrm{kg} /$ day, with $99 \%$ of patients having received $<5 \mathrm{mg} / \mathrm{kg} /$ day.

Therefore, clinicians managing patients with systemic lupus erythematosus (SLE) must be aware that HCQ retinal toxicity mostly depends on the daily dose. Treating patients with $<5 \mathrm{mg} / \mathrm{kg} /$ day would make those kinds of images a real rarity in the future, assuring long-term treatment as the cornerstone of SLE therapy ${ }^{4}$.
Daniel Martín-Iglesias ${ }^{1}[$, MD

Joseba Artaraz ${ }^{2}$, MD

Guillermo Ruiz-Irastorza ${ }^{1,3}$ (D) $\mathrm{PhD}$

${ }^{1}$ Hospital Universitario Cruces, Autoimmune Diseases Research Unit;

${ }^{2}$ Hospital Universitario Cruces, Ophthalmology Department;

${ }^{3}$ University of the Basque Country, Medicine, Barakaldo, Spain.

\section{REFERENCES}

1. Carter KL, Do DV. Hydroxychloroquine-induced retinal toxicity. J Rheumatol 2020;47:632.

2. Melles RB, Marmor MF. The risk of toxic retinopathy in patients on long-term hydroxychloroquine therapy. JAMA Ophthalmol 2014;132:1453-60.

3. Martín-Iglesias D, Artaraz J, Fonollosa A, Ugarte A, Arteagabeitia A, Ruiz-Irastorza G. Evolution of retinal changes measured by optical coherence tomography in the assessment of hydroxychloroquine ocular safety in patients with systemic lupus erythematosus. Lupus 2019;28:555-9.

4. Fanouriakis A, Kostopoulou M, Alunno A, Aringer M, Bajema I, Boletis JN, et al. 2019 update of the EULAR recommendations for the management of systemic lupus erythematosus. Ann Rheum Dis 2019;78:736-45. 